\title{
ANALISIS FAKTOR YANG BERPENGARUH TERHADAP PEMILIHAN RUTE JALAN TOL BALI MANDARA
}

\author{
Adi Susanto, $\mathrm{SH}, \mathrm{MH}$ \\ Dosen STTD \\ J1. Raya Setu no.89 \\ Cibuntu - Cibitung \\ Tlp/Fax : ( 021 ) 8254640
}

Ir. Juliaman Pangaribuan,MM

Dosen STTD

Jl. Raya Setu no.89

Cibuntu - Cibitung

Tlp/Fax : ( 021 ) 8254640

\author{
Ir. Dewa Putu Punia,MT \\ Dosen STTD \\ Jl. Raya Setu no.89 \\ Cibuntu - Cibitung \\ Tlp/Fax : ( 021 ) 8254640
}

\author{
Fery Subekti,MT \\ Dosen STTD \\ Jl. Raya Setu no.89 \\ Cibuntu - Cibitung \\ Tlp/Fax : ( 021 ) 8254640
}

\author{
Ir. Santausa Purnama Salim,MM \\ Dosen STTD \\ J1. Raya Setu no.89 \\ Cibuntu - Cibitung \\ Tlp/Fax : ( 021 ) 8254640
}

\author{
Ricko Yudhanta,M.Sc \\ Dosen STTD \\ J1. Raya Setu no.89 \\ Cibuntu - Cibitung \\ Tlp/Fax : ( 021 ) 8254640
}

\begin{abstract}
Prior to the existence of the Mandara Bali toll road, By-passNgurah Rai was the only primary arterial road connecting the traffic flow of people and goods from Ngurah Rai Airport to Nusa Dua. Traffic on this road is still mixed and many side barriers are commercial areas that lower the level of service, convenience and traffic security that pass through the route. Traffic conditions on the roads can be said to be bad with the level of road service between D and F on the road segments By-passNgurah Rai from / to the Nusa Dua area or from / to Denpasar (Darmendra, 2014) as it will take longer to cross it. This situation is clearly an obstacle to the development of economic and social activities such as the distribution of people and goods in the area of Bali Selatan.Dibangun Bali Mandara toll road aims to provide alternative services and can improve the level of service (level of service) BypassNgurah Rai road or at least restore function and position originally on the road. The route selection analysis is expected to be a reference to reduce the traffic load on the By-passNgurah Rai road.
\end{abstract}

Keywords: Traffic, Toll Road, Bali Mandara

\begin{abstract}
ABSTRAKSI
Sebelum adanya jalan tol Bali Mandara ,By-passNgurah Rai merupakan satu-satunya jalan arteri primer yang menghubungkan arus lalu lintas orang dan barang dari Bandara Ngurah Rai menuju Nusa Dua. Lalu lintas pada jalan ini masih tercampur dan banyak hambatan samping berupa kawasan komersial yang menurunkan tingkat pelayanan, kenyamanan dan keamanan lalu lintas yang melewati rute tersebut. Kondisi lalu lintas pada jalan tersebut bisa dikatakan buruk dengan tingkat pelayanan jalannya antara D sampai dengan $\mathrm{F}$ baik pada ruas-ruas jalan $B y$-pass Ngurah Rai dari/ke arah kawasan Nusa Dua maupun dari/ke arah kota Denpasar (Darmendra, 2014), pada kondisi seperti itu akan memerlukan waktu lebih lama untuk melintasinya. Keadaan tersebut jelas menjadi penghambat perkembangan aktivitas ekonomi dan sosial seperti pendistribusian orang dan barang di wilayah Bali Selatan.Dibangunnya jalan tol Bali Mandara bertujuan untukmemberikan alternatif pelayanan dan dapat meningkatkan tingkat pelayanan (level of service) jalan By-pass Ngurah Rai atau setidaknya mengembalikan fungsi serta kedudukan semula pada ruas jalan tersebut. Dengan análisis pemilihan rute diharapkan dapat menjadi referensi untuk mengurangi beban lalu lintas pada jalan By-passNgurah Rai.
\end{abstract}

Kata Kunci : Lalu Lintas, Jalan Tol, Bali Mandar 


\title{
PENDAHULUAN
}

\author{
Latar Belakang
}

Sebelum adanya jalan tol Bali Mandara ,By-passNgurah Rai merupakan satusatunya jalan arteri primer yang menghubungkan arus lalu lintas orang dan barang dari Bandara Ngurah Rai menuju Nusa Dua. Lalu lintas pada jalan ini masih tercampur dan banyak hambatan samping berupa kawasan komersial yang menurunkan tingkat pelayanan, kenyamanan dan keamanan lalu lintas yang melewati rute tersebut. Kondisi lalu lintas pada jalan tersebut bisa dikatakan buruk dengan tingkat pelayanan jalannya antara $\mathrm{D}$ sampai dengan $\mathrm{F}$ baik pada ruas-ruas jalan $B y$ passNgurah Rai dari/ke arah kawasan Nusa Dua maupun dari/ke arah kota Denpasar (Darmendra, 2014), pada kondisi seperti itu akan memerlukan waktu lebih lama untuk melintasinya. Keadaan tersebut jelas menjadi penghambat perkembangan aktivitas ekonomi dan sosial seperti pendistribusian orang dan barang di wilayah Bali Selatan.Dibangunnya jalan tol Bali Mandara bertujuan untukmemberikan alternatif pelayanan dan dapat meningkatkan tingkat pelayanan (level of service) jalan BypassNgurah Rai atau setidaknya mengembalikan fungsi serta kedudukan semula pada ruas jalan tersebut. Dengan análisis pemilihan rute diharapkan dapat menjadi referensi untuk mengurangi beban lalu lintas pada jalan By-passNgurah Rai.

\section{RUMUSAN MASALAH}

Berdasarkan penjelasan pada bagian sebelumnya, dapat dirumuskan permasalahan yang akan dibahas pada penelitian ini, yaitu:

1. Apa saja variabel yang berpengaruh terhadap penggunaan jalan tol Bali Mandara?

2. Bagaimanakah pengembangan model pemilihan rute jalan tol Bali Mandara dengan menggunakan regresi logistik?

3. Bagaimanakah probabilitas dari masing-masing variabel yang berpengaruhterhadap pemilihan rute jalan tol?

\section{Tujuan Penelitian}

Sebagai dasar pelaksanaan studi harus dilandasi suatu tujuan yang dijadikan acuan dalam studi ini, yaitu:

1. Menganalisis variabel yang berpengaruh terhadap penggunaan jalan tol Bali Mandara.

2. Mengembangkan model pemilihan rute jalan tol dengan variabel-variabel yang mempengaruhinya menggunakan regresi logistik.

3. Menganalisis probabilitas dari masing-masing variabel yang berpengaruh terhadap pemilihan rute jalan tol.

\section{Manfaat Penelitian}

Manfaat penelitian dalam penelitian ini adalah sebagai berikut:

1. Hasil dari penelitian ini dapat dimanfaatkan untuk menganalisis hubungan sebab akibat dengan faktor-faktor yang berpengaruh signifikan, sehingga dapat digunakan untuk memprediksi suatu kejadian baik memilih/tidak memilih rute jalan tol.

2. Bagi praktisi/instansi terkait adalah sebagai tambahan informasi kepada pihakpihak terkait tentang model pemilihan rute jalan tol serta dapat mempermudah 
menggambarkan kondisi nyata di lapangan dalam bentuk matematis, sehingga bisa menjadi controluntuk meningkatkan kualitas layanan dan dapat । kan sebagai referensi dalam rangka pemecahan masalah.

3. Bagi Perguruan Tinggi, penelitian ini diharapkan dapat memperkayakhasanah penelitian di bidang transportasi.

4. Bagi Peneliti adalah sebagai bahan acuan untuk peneliti dan pengembangan selanjutnya pada bidang transportasi.

\section{TINJAUAN PUSTAKA}

\section{Pengertian Jalan Tol}

Jalan tol adalah jalan umum yang merupakan bagian sistem jaringan jalan dan sebagai jalan nasional yang penggunanya diwajibkan membayar tarif tol. Syaratsyarat Jalan Tol

\section{Spesifikasi Jalan Tol}

Dalam Pasal 6 Peraturan Pemerintah Republik Indonesia No. 15 Tahun 2005 jalan tol harus mempunyai spesifikasi sebagai berikut:

1. Tidak ada persimpangan sebidang dengan ruas jalan lain atau dengan prasarana transportasi lainnya.

2. Jumlah jalan masuk dan jalan keluar ke dan dari jalan tol dibatasi secara efisien dan semua jalan masuk dan jalan keluar harus terkendali secara penuh.

3. Jarak antarsimpang susun, paling rendah $5 \mathrm{~km}$ untuk jalan tol luar perkotaan dan paling rendah $2 \mathrm{~km}$ untuk jalan tol perkotaan.

4. Jumlah lajur sekurang-kurangnya dua lajur per arah.

5. Menggunakan pemisah tengah atau median.

\section{METODE PENELITIAN}

\section{Rancangan Penelitian}

Penelitian dimulai dengan pengumpulan data baik data primer maupun sekunder dengan melaksanakan survei. Dengan berdasarkan tujuan-tujuan jelas, maka data yang mendukung segera dikumpulkan. Proses ini meliputi kegiatan yang dimulai dari persiapan pengumpulan data yaitu pembuatan form kuesioner, pembuatan ijin dan pemberitahuan kepada instansi terkait, survei pendahuluan, penentuan jumlah sampel dan perekrutan anggota tim survei, serta teknis pelaksanaan survei. Data primer didapatkan dari menyebarkan kuesioner ke responden (pengguna jalan), sedangkan data sekunderdiperoleh dari instansi terkait. 


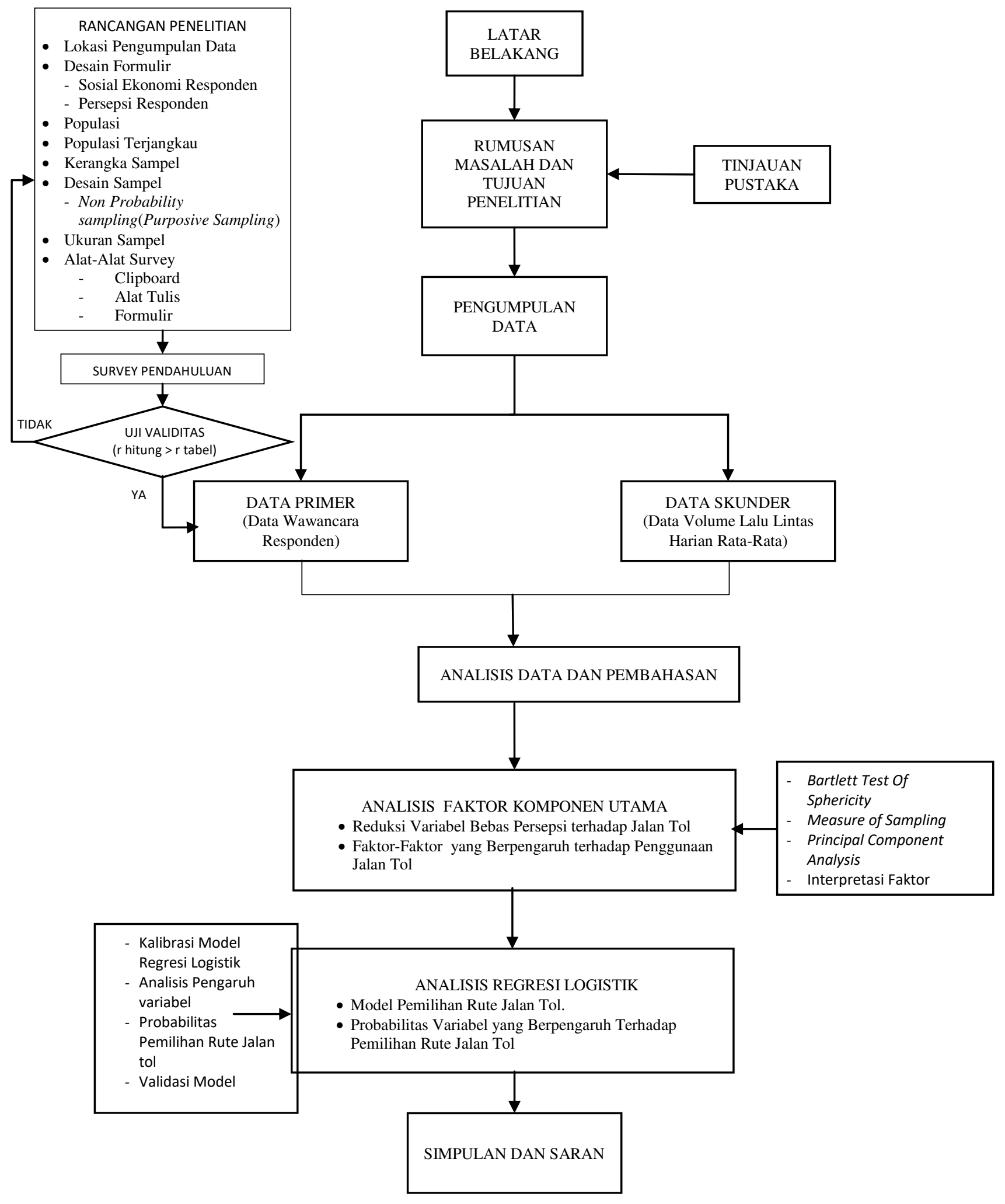

Gambar 3.1Rancangan Penelitian 


\section{Lokasi Penelitian}

Jalan Tol di Atas Permukaan Laut Bali Mandara adalah merupakan jalan tol pertama di Provinsi Bali. Jalan ini menghubungkan Nusa Dua, Ngurah Rai dan Benoa. Dengan panjang total $12,7 \mathrm{Km}$ dan sebagian besar berada di atas permukaan laut, jalan tol ini menjadi jalur alternatif untuk menuju bandara dan kawasan Nusa Dua. Lokasi pengumpulan data ditentukan pada tiga titik lokasi didekat gerbang jalan tol Bali Mandara. Lokasi survei dilaksanakan di Benoa, Bandara Ngurah Rai, dan Nusa Dua.

\section{Penentuan Sumber Data}

Untuk mencapai tujuan penelitian ini, maka data yang dibutuhkan adalah sebagai berikut:

1. Data Primer

2. Data Sekunder

\section{Analisis Data}

Untuk mencapai tujuan Pada penelitian ini, analisis data yang dilakukan pada penelitian ini dilakukan secara berurutan. Analisis yang dilakukan pertama adalah analisis faktor (analisis komponen utama), selanjutnya adalah analisis regresi logistik. Dari faktor-faktor (variabel) yang terbentuk melalui analisis komponen utama, akan dianalisis dengan proses analisis regresi logistik bersama variabel lainnya (variabel sosial ekonomi pengguna jalan tol Bali Mandara).

\section{HASIL DAN PEMBAHASAN}

Uji Validitas dan Reliabilitas

Sebelum dilakukan pengumpulan data, pertanyaan didalam kuesioner diuji terlebih dahulu untuk mengetahui validitas dan reliabilitas. Hasil dari uji validitas dan reliabilitas pada 30 responden ditunjukkan pada Tabel 4.1 sebagai berikut:

Tabel 4.1Hasil Uji Validitas dan Reliabilitas Kuesioner Penelitian

\begin{tabular}{lcc}
\hline Item & $\begin{array}{l}\text { Corrected } \\
\text { Item-Total } \\
\text { Correlation }\end{array}$ & CronbachAlpha \\
\cline { 1 - 2 } & 0.411 & \\
\hline $\begin{array}{l}\text { Kesesuaian tarif } \\
\text { dengan mensi waktu perjalanan } \\
\text { jalan tol }\end{array}$ & 0.490 & .802 \\
\hline Aksesibilitas & 0.429 & \\
\hline Sistem Informasi & 0.371 & \\
\hline Kelancaran lalu lintas & 0.612 & \\
\hline
\end{tabular}




\begin{tabular}{ll} 
Kualitas perkersaan jalan & 0.536 \\
\hline $\begin{array}{l}\text { Keselamatan dalam } \\
\text { menggunakan jalan tol }\end{array}$ & 0.432 \\
\hline $\begin{array}{l}\text { Kenyamanan } \\
\text { menggunakan jalan tol }\end{array}$ & 0.683 \\
\hline $\begin{array}{l}\text { Keamanan menggunakan } \\
\text { jalan tol }\end{array}$ & 0.530 \\
\hline Penerangan & 0.446 \\
\hline $\begin{array}{l}\text { Rambu lalu lintas } \\
\text { Kemudahan mendapatkan } \\
\text { layanan jalan tol }\end{array}$ & 0.518 \\
\hline Pemandangan & 0.398 \\
\hline
\end{tabular}

Dari tabel di atas dapat dilihat bahwa sebagian besar nilai $r$ hitung (koefisien korelasi) pada masing-masing pernyataan lebih besar dari pada nilai $\mathrm{r}$ tabel pada tingkat signifikansi 5\% (0.361) sehingga dapat dikatakan valid. Hasil uji kuesioner menunjukkan bahwa nilai alpha 0,806 dan lebih besar dari nilai 0,60 sehingga semua pertanyaan di atas dinyatakan reliabel.Dari hasil uji validitas dan reliabilitas maka kuesioner dapat digunakan untuk pengumpulan data.

\subsection{Karakteristik Responden}

Kuesioner yang digunakan berju menjadi tiga titik lokasi pengumpulan ( 72 381, dari 381 kuesioner tersebut dibagi esuai dengan komposisi yang diperoleh dari data sekuder (volume lalu lintas harian rata-rata jalan tol Bali Mandara). Semua responden mengisi identitas dan pertanyaan pada kuesioner secara lengkap. Responden yang mengisi kuesioner ini telah sesuai dengan kriteria yang ditetapkan yaitu calon pengguna jalan dengan tujuan perjalanan yang memungkinkan untuk memilih rute jalan tol.

\subsection{1}

Dari keseluruhan responden, berdasarkan pilihan rutenya diklasifikasikan menjadi 2 (dua) macam, yaitu pengguna jalan tol dan jalan non tol. Masing-masing responden memiliki alasan dalam pemilihan rutenya. Responden diminta mengisi bagaimana persepsiterhadap jalan tol sehingga mempengaruhi pemilihan rutenya berdasarkan skala 5 sampai dengan 1, dimana skala 5 merupakan interpretasi dari faktor alasan yang paling utama/sangat puas, dan skala 1 merupakan prioritas alasan terakhir/sangat tidak puas. Dari ketiga titik lokasi survei, didapatkan data persepsi pengguna jalan terhadap jalan tol Bali Mandara sebagai berikut.PadaTabel 4.2menunjukkan total dari ketiga lokasi titik survei Persepsi Pengguna Jalan Terhadap Jalan Tol Bali Mandara faktor pemandangan menjadi pilihan paling banyak dipilih oleh responden $(8,95 \%)$. Hal ini menunjukkan bahwa daya tarik pengguna jalan terhadap jalan tol Bali Mandara saat ini dipilih karena pengguna ingin menikmati pemandangan yang juga menjadi daya tarik dari jalan tol Bali Mandara yang merupakan satu-satunya jalan tol di Indonesia yang berada diatas permukaan laut. Setelah faktor pemandangan diikuti faktor kenyamanan dan keamanan $(8,53 \%$ dan $8,08 \%)$. Akumulasi dari faktor tarif menunjukkan bahwa 
responden belum puas dengan tarif yang ditetapkan (5,99\%), hal ini dikarenakan tarif tol Bali Mandara dirasa oleh responden relatif mahal untuk panjang jalan tol yang tidak terlalu panjang.

Tabel 4.2Persepsi Pengguna Jalan Terhadap Jalan Tol Bali Mandara

\begin{tabular}{llcc}
\hline No & Persepsi Pengguna Jalan Terhadap Jalan Tol & $\begin{array}{c}\text { Akumulasi } \\
\text { Nilai }\end{array}$ & $\begin{array}{c}\text { Prosentase } \\
(\%)\end{array}$ \\
\hline 1 & Kesesuaian tarif & 1078 & 5.99 \\
\hline 2 & Efisiensi waktu perjalanan dengan menggunakan jalan tol & 1434 & 7.97 \\
\hline 3 & Aksesibilitas & 1237 & 6.87 \\
\hline 4 & Sistem Informasi & 1338 & 7.43 \\
\hline 5 & Kelancaran lalu lintas & 1345 & 7.47 \\
\hline 6 & Kualitas perkersaan jalan & 1433 & 7.96 \\
\hline 7 & Perasaan tentang keselamatan dalam menggunakan jalan tol & 1349 & 7.49 \\
\hline 8 & Kenyamanan menggunakan jalan tol & 1436 & 8.08 \\
\hline 9 & Keamanan menggunakan jalan tol & 1536 & 8.53 \\
\hline 10 & Penerangan & 1455 & 7.98 \\
\hline 11 & Rambu lalu lintas & 1425 & 7.92 \\
\hline 12 & Kemudahan dalam mendapatkan layanan jalan tol & 1322 & 7.34 \\
\hline 13 & pemandangan & 1611 & 8.95 \\
\hline & & 17999 & 100 \\
\hline
\end{tabular}

\section{SIMPULAN DAN SARAN}

\subsection{Simpulan}

Dari hasil analisis yang dilakukan pada bab sebelumnya, makadisimpulkan seperti berikut ini:

1. Variabel-variabel yang berpengaruh (signifikan) pada pemilihan pengguna kendaraaan bermotor terhadap penggunaan jalan tol Bali Mandara adalah pendapatan keluarga per bulan $\left(X_{3}\right)$, jarak tempuh harian rata-rata $\left(X_{4}\right)$, dan faktor persepsi terhadap kenyamanan dan keamanan berlalu lintas $\left(F_{1}\right)$.

2. Model pemilihan rute Jalan Tol Bali Mandara dengan menggunakan metode regresi logistikadalah sebagai berikut:

$$
\begin{aligned}
\ln \left[\frac{\mathrm{p}}{(1-\mathrm{p})}\right]= & 2.861-0.235 \mathrm{X}_{1}(1)+0.951 \mathrm{X}_{2}(1)-0.014 \mathrm{X}_{2}(2)+0.093 \mathrm{X}_{2}(3) \\
& -0.890 \mathrm{X}_{3}(1)-2.267 \mathrm{X}_{4}(1)-0.994 \mathrm{X}_{4}(2)-2.628 \mathrm{~F}_{1}(1)-1.863 \mathrm{~F}_{1}(2) .
\end{aligned}
$$

3. Probabilitas Variabel yang Berpengaruh (Signifikan) pada pemilihan rute jalan tol Bali Mandara adalah sebagai berikut:

a. Pengendara kendaraan bermotor yang mempunyai pendapatan keluarga per bulan antara Rp. 2-4 juta $\left(\mathrm{X}_{3}(1)\right)$ dibandingkan dengan mereka yang lebih besar dari Rp. 4 juta, lebih kecil 58,9\% (0.411-1) kemungkinannya untuk menggunakan jalan tol. 
b. Pengendara kendaraan bermotor yang mempunyai jarak tempuh harian rata-rata kurang dari $10 \mathrm{~km}\left(\mathrm{X}_{4}(1)\right)$ dibandingkan dengan mereka yang lebih jauh dari $20 \mathrm{~km}$, lebih kecil 89,6\% (0.104-1) kemungkinannya untuk menggunakan jalan tol.

c. Pengendara kendaraan bermotor yang mempunyai jarak tempuh harian rata-rata antara $10-20 \mathrm{~km}\left(\mathrm{X}_{4}(2)\right)$ dibandingkan dengan mereka yang lebih jauh dari $20 \mathrm{~km}$, lebih kecil 63\% (0.370-1) kemungkinannya untuk menggunakan jalan tol.

d. Pengendara kendaraan bermotor yang menyatakan tidak puas terhadap kenyamanan dan keamanan dalam menggunakan jalan tol $\left(F_{1}(1)\right)$ dibandingkan dengan mereka yang menyatakan puas, lebih kecil 92,8\% (0.072-1) kemungkinannya untuk menggunakan jalan tol.

e. Pengendara kendaraan bermotor yang menyatakan netral terhadap kenyamanan dan keamanan dalam menggunakan jalan tol $\left(F_{1}(1)\right)$ dibandingkan dengan mereka yang menyatakan puas terhadap kelancaran lalu lintas, lebih kecil $84,5 \% \quad(0.155-1)$ kemungkinannya untuk menggunakan jalan tol.

\subsection{Saran}

Berdasarkan hasil penelitian ini, maka saran yang dapat disampaikan adalahsebagai berikut:

1. Penelitian ini dapat dikembangkan lagi dengan menggunakan variabel bebas yang lain, karena menurut hasil validasi masih ada beberapavariabel atau faktor-faktor lain yang dapat menjelaskan sekitar $67 \%$ variabel dependen yang belum dianalisis pada pengembangan model dalam penelitian ini, sehingga didapat hasil pemodelan yang lebih akurat.

2. Pada penelitian ini hanya menganalisis anatara dua kemungkinan yaitu menggunakan jalan tol atau tidak menggunakan jalan tol tanpa mempertimbangkan ruas-ruas jalan yang ada. Untuk itu diperlukan kajian pemilihan rute lebih lanjut dengan memperhatikan ruas-ruas jalan yang ada, agar hasilnya lebih bermaanfaat

3. Terdapat berbagai metode untuk membangun model pemilihan rute. Dianjurkan menggunakan model lain (bukan regresi logistik),sehingga hasilnya dapat digunakan sebagai pembanding di dalam pemilihan rute jalan tol Bali Mandara.

4. Model yang terbangun hanya dapat dipergunakan pada jalan tol Bali Mandara. Perlu dilakukan penyempurnaan pada penelitian ini dengan mengambil data pada beberapa studi kasus lain, sehingga dapat diterapkanstudi kasus yang berbeda. 


\section{DAFTAR PUSTAKA}

Adiningsih, S. dan Kadarusman. 2003. Teori Ekonomi Mikro, Edisi Kedua. Yogyakarta: BPFE.

Agresti, A. 1996.Categorical Data Analysis. New York: John Wiley and Sons.

Al-Ghamdi, A.S. 2002. Using Logistic Regression To Estimate The Influence of Accident Factors on Accident Severity, Accident Analysis and Prevention. Volume 34:Pp.729-741.

Arikunto. 2002. Prosedur Penelitian Suatu Pendekatan Praktik. Jakarta: Rhineka Cipta

Darmendra, I.P.Y. 2014. "Pemanfaatan Citra Quickbird Dan Sistem Informasi Geografis Untuk Rekomendasi Manajemen Jalan Di Kota Denpasar" (Tesis). Medan: Universitas Sumatera Utara.

Finkleman, J., Casello, J., Liping.2011.Empirical Evidence From The Greater TorontoArea On The Acceptability And Impacts Of HOT Lanes, Transport Policy 18.Pp. 814824.

Fyhri, A. and Backer-Grondahl, A. 2012. Personality and Risk Perception in Transport.Accident AnalisysPrevention. Volume 49, Pp. 470-475.

Ghozali, I. 2005. Aplikasi: Analisis Multivariate dengan Program SPSS, Edisi 3. Semarang: Badan Penerbit Universitas Diponegoro.

Gilarso, S.J. 2003. Pengantar ilmu Ekonomi Mikro. Yogyakarta: Kanisius.

Gorsuch, R. L. 1974. Factor Analysis. Philadephia: Saunders Company.

Hair, J. F. 1992. Multivariate Data Analysis. New York: Macmilan Publishing Company.

Hassan, H. and Abdel-Aty M. 2013. Predicting Reduced Visibility Related Crashes on Freeways Using Real-Time Traffic Flow Data.Journal of Safety Research. Volume45: pp. 29- 36.

Hooper, D., Coughlan, J., Mullen, M. Structural Equation Modelling: Guidelines for Determining Model Fit. Electronic Journal of Business Research Methods, Volume6: Pp. 53-60.

Hosmer, D. W.and Lemeshow, S.1989. Applied Logistic Regression. New York: John Wiley and Sons.

Imam, S. B. 2012. "Analisis Hubungan Rata-Rata IPK dan Lama Studi Mahasiswa ITS dengan Web Personal Dosen ITS dengan Menggunakan Analisis Faktor". (Tesis).Surabaya: Institut Teknologi Sepuluh November. 
